\title{
Males and females exhibit similar muscle glycogen recovery with varied recovery food sources
}

\author{
Shannon Flynn ${ }^{1} \cdot$ Alejandro Rosales $^{1} \cdot$ Walter Hailes $^{1} \cdot$ Brent Ruby $^{1}$
}

Received: 16 December 2019 / Accepted: 18 March 2020 / Published online: 25 March 2020

(c) The Author(s) 2020

\begin{abstract}
Purpose Research has elucidated the impact of post-exercise carbohydrate nutrition and environmental conditions on muscle glycogen re-synthesis. However, research has minimally considered the implications of glycogen recovery in females and has mostly focused on commercial sport nutrition products. The purpose of this study was to determine the effects of varied mixed macronutrient feedings on glycogen recovery and subsequent exercise performance in both sexes.

Methods Males $(n=8)$ and females $(n=8)$ participated in a crossover study. Subjects completed a 90-min cycling glycogen depletion trial, then rested for $4 \mathrm{~h}$. Two carbohydrate feedings $\left(1.6 \mathrm{~g} \mathrm{~kg}^{-1}\right)$ of either sport supplements or potato-based products were delivered at 0 and $2 \mathrm{~h}$ post-exercise. Muscle biopsies (glycogen) and blood samples (glucose, insulin) were collected during the recovery. Afterwards, subjects completed a $20 \mathrm{~km}$ cycling time trial.

Results There was no difference between sexes or trials for glycogen recovery rates (male: $7.9 \pm 2.7$, female: $8.2 \pm 2.7$, potato-based: $8.0 \pm 2.5$, sport supplement: $8.1 \pm 3.1 \mathrm{mM} \mathrm{kg}$ wet $\mathrm{wt}^{-1} \mathrm{~h}^{-1}, p>0.05$ ). Time trial performance was not different between diets $(38.3 \pm 4.4$ and $37.8 \pm 3.9$ min for potato and sport supplement, respectively, $p>0.05)$.

Conclusions These results indicate that food items, such as potato-based products, can be as effective as commercially marketed sports supplements when developing glycogen recovery oriented menus and that absolute carbohydrate dose feedings $\left(\mathrm{g} \mathrm{kg}^{-1}\right)$ can be effectively applied to both males and females.
\end{abstract}

Keywords Glycogen re-synthesis $\cdot$ Post-exercise recovery $\cdot$ Sex differences $\cdot$ Sports supplements

$\begin{array}{ll}\text { Abbreviations } \\ \text { ANOVA } & \text { Analysis of variance } \\ \text { BBM } & \text { Beats per minute } \\ \text { CHO } & \text { Carbohydrate } \\ \text { FFM } & \text { Fat-free mass } \\ \text { HR } & \text { Heart rate } \\ \text { PB } & \text { Potato-based foods } \\ \text { PTT } & \text { Practice time trial } \\ \text { RER } & \text { Respiratory exchange ratio } \\ \text { RPE } & \text { Rating of perceived exertion } \\ \text { TT } & \text { Time trial } \\ \text { SS } & \text { Sport supplement products }\end{array}$

Communicated by Michael Lindinger.

Brent Ruby

brent.ruby@mso.umt.edu

1 Montana Center for Work Physiology and Exercise Metabolism, College of Integrative Physiology and Athletic Training, The University of Montana, McGill Hall, Missoula, MT 59812, USA

$$
\begin{array}{ll}
\text { VAS } & \text { Visual analog scale } \\
V \mathrm{O}_{2 \text { Peak }} & \text { Peak oxygen uptake } \\
W_{\text {Max }} & \text { Maximal power output }
\end{array}
$$

\section{Introduction}

Endurance exercise performance and time to exhaustion have historically been linked to initial levels of glycogen storage within the skeletal muscle (Ahlborg et al. 1967; Bergstrom et al. 1967). Additionally, given the expected depletion rates of glycogen and the finite storage capacity within the muscle, sport nutrition guidelines have developed evidence-based strategies to optimize glycogen recovery after fuel-depleting training or competition. Most commonly, these recommendations suggest a systematic increase in dietary carbohydrate (Blom et al. 1987; Ivy et al. 1988a, b) or mixed diet sources (Ivy et al. 2002; Jentjens et al. 2001; Tarnopolsky et al. 1997; van Loon et al. 2000) in a timely fashion post-glycogen-compromising or -depleting exercise. Collectively, the underlying rates of glycogen re-synthesis 
are influenced by the extent of glycogen depletion (Price et al. 1994; Zachwieja et al. 1991), the timing of ingestion (Ivy et al. 1988a), dose and amount (Blom et al. 1987; Ivy et al. 1988b; Jentjens et al. 2001; van Loon et al. 2000), the composition as either varied carbohydrate source (Blom et al. 1987; Burke et al. 1993; Ivy et al. 1988a, b; Kions et al. 1990; Reed et al. 1989) or in combination with amino acid blends or protein (Ivy et al. 2002; Jentjens et al. 2001; Tarnopolsky et al. 1997; van Loon et al. 2000; Zawadski et al. 1992), and most recently ambient (Naperalsky et al. 2010) and skeletal muscle temperature (Slivka et al. 2012; Tucker et al. 2012).

When compared to sport nutrition products, food items have demonstrated success in promoting 4-h glycogen resynthesis rates. Both chocolate milk (Lunn et al. 2012) and fast food items (Cramer et al. 2015) restore glycogen similarly to common commercial sport nutrition products. Chocolate milk (Karp et al. 2006; Lunn et al. 2012; Pritchett et al. 2009; Thomas et al. 2009) and fast food (Cramer et al. 2015) also impact subsequent exercise performance similarly to commercial sport nutrition items. Collectively, these data demonstrate that a variety of dietary strategies can be effective in promoting glycogen re-synthesis following a bout of glycogen-depleting exercise.

Recommendations for optimal re-synthesis appear uniformly applied to both men and women despite a relatively small amount of research including female participants. When comparing women to men, research provides conflicting results regarding both the impacts of glycogen supercompensation (or pre-loading) (James et al. 2001; Paul et al. 2001; Tarnopolsky et al. 2001; Walker et al. 2000) and substrate use during endurance exercise (Devries 2016; Riddell et al. 2003; Roepstorff et al. 2002; Ruby et al. 2002a; Tarnopolsky and Ruby 2001). However, most of the subtle metabolic differences previously demonstrated appear associated with circulating levels of endogenous and exogenous estradiol. This has been the topic of multiple reviews (Tarnoposky and Ruby 2001; Tarnoposky 2008).

These investigations illustrate both similarities and differences between males and females, however, few directly report post-exercise glycogen re-synthesis rates for both sexes (Tarnopolsky et al. 1997). Exogenous provision of adequate substrate in the form of liquid supplements yields comparable glycogen restoration for men and women, but subsequent exercise performance has not been previously evaluated following a post-exercise carbohydrate feeding recovery period (Tarnopolsky et al. 1997).

The purpose of the present investigation was to compare glycogen recovery and subsequent exercise performance in males and females following ingestion of either a potatoderived mixed macronutrient diet or commercial sport nutrition oriented diet. Key dependent measures included rates of muscle glycogen re-synthesis and $20 \mathrm{~km}$ cycling time trial performance. We hypothesized that there would be minimal differences in glycogen re-synthesis or exercise performance between the two recovery diets with similar macronutrient distribution. We further hypothesized that males and females would demonstrate similar rates of glycogen re-synthesis when total exogenous carbohydrate was provided proportional to total body weight $\left(1.6 \mathrm{~g} \mathrm{~kg}^{-1}\right)$.

\section{Methods}

\section{Participants}

Recreationally active subjects $(N=16 ; n=8$ males and $n=8$ females) completed the study. The study subjects were healthy, injury-free, and familiar with endurance exercise (refer to Table 2 for descriptive statistics). All of the female subjects were currently using supplemental hormone prescriptions (triphasic norethindrone and ethyl estradiol, oral pill, $n=4$ ) or time-release (intrauterine device, $n=4$ ) birth control. All subjects completed a Physical Readiness Questionnaire (PAR-Q) and gave written informed consent prior to the study. Prior to subject recruitment and subsequent testing, all procedures were approved by the university's internal review board (IRB).

\section{Preliminary testing}

Each subject fasted for $4 \mathrm{~h}$ and abstained from exercise, alcohol, and caffeine for $24 \mathrm{~h}$ prior to an initial visit. After measuring body mass and height, body composition was obtained via hydrodensitometry with corrections for estimated residual lung volume (Goldman and Becklake 1959). Underwater body mass was obtained using an electronic scale (Exertech, Dreshbach, MN, USA) to calculate body density. Sex-specific equations were utilized to convert body density to percent body fat (American College of Sports Medicine ).

Using a cycle ergometer (Velotron, RacerMate Inc., Seattle, WA, USA), peak oxygen uptake $\left(V \mathrm{O}_{2 \text { Peak }}\right)$ and maximal power output $\left(W_{\text {Max }}\right)$ were determined for each subject during a graded exercise protocol. The protocol started at $95 \mathrm{~W}$ for men and $60 \mathrm{~W}$ for women, increasing $35 \mathrm{~W}$ every $3 \mathrm{~min}$ until volitional fatigue and the achievement of at least two of the following specific max test criteria: respiratory exchange ratio (RER) $>1.10$, plateau in $V \mathrm{O}_{2}$, heart rate (HR) within 10 beats per minute (BPM) of age-predicted max, or rating of perceived exertion $(\mathrm{RPE})>17$. During the test, gas exchange was measured using a calibrated metabolic cart (ParvoMedics, Inc., Salt Lake City, UT, USA). $V \mathrm{O}_{2 \text { peak }}$ was calculated as the highest $15 \mathrm{~s}$ average oxygen uptake and $W_{\text {Max }}$ was calculated using the following equation: $W_{\mathrm{Max}}=$ (power output 
in $W$ during last completed stage $)+(($ final stage time before fatigue in $\mathrm{s} / 180 \mathrm{~s}) \times 35 \mathrm{~W}$ ).

On the second and third visit, each participant completed a practice (PTT) $20 \mathrm{~km}$ time trial (TT) on a computer-simulated course, totaling two PTT. Subjects were instructed to complete the distance as quickly as possible. Subjects were allowed to electronically change speed and shift gears. Distance and time were recorded using RacerMate Inc. software (RacerMate, Inc., Seattle, WA, USA). These sessions were designed to familiarize subjects with the instrumentation, ensuring TT competency prior to the experimental trials.

\section{Experimental design}

Subjects completed two trials in a crossover, counter-balanced design with 7 days between trials. Females were tested without attempting to control timing across the menstrual cycle. Subjects were instructed to consume a mixed diet the day before each trial and keep a dietary record of all foods and drinks consumed in the $24 \mathrm{~h}$ prior to their initial experimental trial. This food record was then used to repeat the same $24 \mathrm{~h}$ pre-dietary intake for the subsequent experimental trial. For each laboratory visit, subjects arrived following a 12-h fast, while at the same time refraining from exercise, alcohol, and caffeine for the previous $24 \mathrm{~h}$. For each trial, participants completed a glycogen depletion ride, a 4-h recovery period, and a $20 \mathrm{~km}$ TT. During the recovery, subjects consumed one of two mixed macronutrient diets (sports supplement products $=$ SS, potato-based foods $=$ PB, refer to Table 1 ) . To maintain a similar carbohydrate dose for all subjects (approximately $1.6 \mathrm{~g} \mathrm{~kg}^{-1}$ ), one of four unique serving sizes was assigned to each participant based upon body mass ranges from preliminary testing. Subjects completed gastrointestinal discomfort and meal satisfaction questionnaires and muscle biopsies and blood samples were collected throughout the recovery period. Figure 1 illustrates the experimental design.

Table 1 Bolus feeding protocol for $0 \mathrm{~h}$ and $2 \mathrm{~h}$ post-exercise recovery for body mass of $62-74 \mathrm{~kg}$

\begin{tabular}{|c|c|c|c|c|c|}
\hline & Calories & Fat $(\mathrm{g})$ & Carb $(g)$ & Protein $(\mathrm{g})$ & Sodium (mg) \\
\hline \multicolumn{6}{|l|}{ Sports supplement } \\
\hline \multicolumn{6}{|l|}{$0 \mathrm{~h}$} \\
\hline Rehydrate Salt Tablet & 0 & 0 & 0 & 0 & 800 \\
\hline Powerade Mountain Berry Blast (591 mL) & 130 & 0 & 35 & 0 & 250 \\
\hline Lara Bar Peanut Butter Chocolate Chip & 440 & 22 & 52 & 12 & 120 \\
\hline Gatorade Prime Energy Chews Fruit Punch (Six Chews) & 83 & 0 & 20 & 0 & 58 \\
\hline Total & 653 & 22 & 107 & 12 & 1228 \\
\hline \multicolumn{6}{|l|}{$2 \mathrm{~h}$} \\
\hline Rehydrate Salt Tablet & 0 & 0 & 0 & 0 & 800 \\
\hline Gatorade Lemon-Lime (591 mL) & 140 & 0 & 36 & 0 & 270 \\
\hline Cliff Mojo Bar Mountain Mix & 400 & 18 & 46 & 20 & 480 \\
\hline Cliff Bloks Energy Chews Mountain Berry (Six Bloks) & 117 & 0 & 28 & 0 & 58.5 \\
\hline Total & 657 & 18 & 110 & 20 & 1609.5 \\
\hline $4 \mathrm{~h}$ total & 1310 & 40 & 217 & 32 & 2836.5 \\
\hline \multicolumn{6}{|l|}{ Potato based } \\
\hline \multicolumn{6}{|l|}{$0 \mathrm{~h}$} \\
\hline Kraft Pancake Syrup & 105 & 0 & 28 & 0 & 0 \\
\hline Simplot Old European Potato Pancakes & 240 & 10 & 34 & 4 & 620 \\
\hline Mott's Unsweetened Applesauce & 40 & 0 & 10 & 0 & 0 \\
\hline Great Value Hash Brown & 300 & 16 & 36 & 4 & 540 \\
\hline Total & 685 & 26 & 108 & 8 & 1160 \\
\hline \multicolumn{6}{|l|}{$2 \mathrm{~h}$} \\
\hline Delallo Potato Gnocchi (140 g) & 345 & 0 & 75 & 9 & 840 \\
\hline Prego Traditional Pasta Sauce (120 mL) & 70 & 1.5 & 13 & 2 & 480 \\
\hline Great Value Seasoned Fries (84 g) & 175.5 & 9.4 & 21 & 2.3 & 410 \\
\hline Total & 590.5 & 10.9 & 109 & 13.3 & 1730 \\
\hline $4 \mathrm{~h}$ total & 1275.5 & 36.9 & 217 & 21.3 & 2890 \\
\hline
\end{tabular}




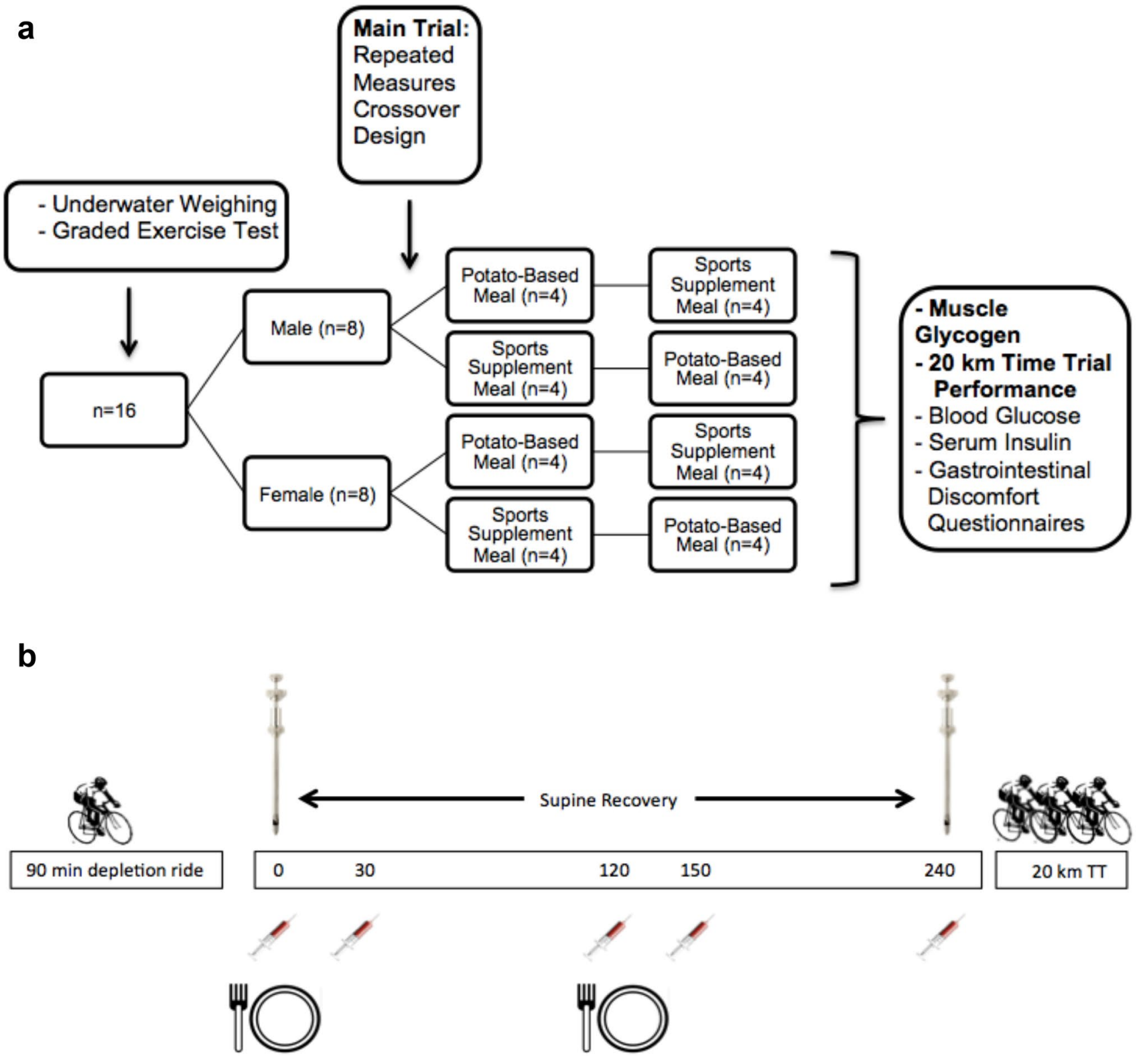

Fig. 1 a Study design with dependent measures included (primary measures in bold), b main experimental trial design

\section{Glycogen depletion protocol during main experimental trials}

Subjects completed a 90-min cycle ergometer glycogendepleting ride. The protocol consisted of a 10-min warm up at $55 \% W_{\text {Max }}$, a series of 10 intervals (2 min at $80 \% W_{\text {Max }}$ followed by $4 \mathrm{~min}$ at $50 \% W_{\mathrm{Max}}$ ) lasting $60 \mathrm{~min}, 8 \mathrm{~min}$ at $60 \% W_{\text {Max }}$, and $12 \mathrm{~min}$ at $50 \% W_{\text {Max }}$. Water was consumed ad libitum during the exercise. Exercise occurred in laboratory ambient conditions of $20{ }^{\circ} \mathrm{C}, 25-30 \%$ relative humidity with a light fan. Following the depletion ride, participants rested in a seated or reclined position for a 4-h recovery period. Recovery was completed in the same ambient temperature environment but without the fan.

\section{Feeding strategy}

At $0 \mathrm{~h}$ and $2 \mathrm{~h}$ of recovery, participants consumed one of two mixed macronutrient diets with equivalent macronutrient distributions (SS or PB). Nutrition label serving sizes were used to match macronutrients, while items were additionally weighed for accuracy. Each subject consumed $1.6 \mathrm{~g}$ carbohydrate kg body weight ${ }^{-1}$ for each feeding. Fat and protein content were also comparable between trials. Table 2 
Table 2 Descriptive data

\begin{tabular}{lccl}
\hline Characteristic & Men $(n=8)$ & Women $(n=8)$ & Significance $(p$ value $)$ \\
\hline Age (years) & $27.1 \pm 6.8$ & $25.1 \pm 4.8$ & NS \\
Weight $(\mathrm{kg})$ & $70.9 \pm 8.3$ & $59.2 \pm 4.8$ & $p<0.01$ \\
Fat-free mass $(\mathrm{kg})$ & $62.9 \pm 5.7$ & $48.4 \pm 4.9$ & $p<0.001$ \\
Body fat $(\%)$ & $14.6 \pm 4.2$ & $18.3 \pm 5.8$ & $\mathrm{NS}$ \\
$V \mathrm{O}_{2 \text { peak }}\left(\mathrm{L} \mathrm{min}^{-1}\right)$ & $4.0 \pm 0.2$ & $2.8 \pm 0.4$ & $p<0.0001$ \\
$V \mathrm{O}_{2 \text { peak }}\left(\mathrm{mL} \mathrm{kg}^{-1} \mathrm{~min}^{-1}\right)$ & $56.7 \pm 4.2$ & $46.5 \pm 6.6$ & $p<0.01$ \\
$V \mathrm{O}_{2 \text { peak }}\left(\mathrm{mL} \mathrm{kg} \mathrm{FFM}^{-1} \mathrm{~min}^{-1}\right)$ & $63.8 \pm 5.0$ & $57.2 \pm 6.3$ & $\mathrm{NS}$ \\
\hline
\end{tabular}

Values are means $\pm \mathrm{SD}$

$N S$ not significant, $p$ values by independent $t$ test

provides details in reference to specific menu items and feeding schedules.

\section{Questionnaires}

Subjects completed gastrointestinal discomfort questionnaires at $0,1,2,3$, and $4 \mathrm{~h}$ of recovery and post-meal questionnaires at 0 and $2 \mathrm{~h}$ of recovery. The gastrointestinal discomfort questionnaire gauged hunger, fullness, sickness, and stomach discomfort. The post-meal questionnaire evaluated meal satisfaction, taste, and acceptability. Both questionnaires involved a $150 \mathrm{~mm}$ visual analog scale (VAS) with "Not at all" on the left edge and "Extremely" on the right edge of the continuum. Participants placed an " $X$ " along the scale for each question. The distance from "Not at all" in millimeter was divided by $150 \mathrm{~mm}$ and reported as a score (Kissileff et al. 2003).

\section{$20 \mathrm{~km}$ time trial}

After the recovery, subjects completed a $20 \mathrm{~km}$ cycle ergometer TT described above with the same conditions each trial. Participants were instructed to complete the distance as rapidly as possible. Subjects were not provided encouragement or entertainment and were blinded to time and intensity. Distance and time were recorded similarly to the PTT. Subjects did not consume water during the TTs.

\section{Tissue and blood sampling and analysis}

\section{Muscle biopsies}

At 0 and $4 \mathrm{~h}$ of recovery post-glycogen-depleting exercise, muscle biopsies from the vastus lateralis were extracted using the percutaneous biopsy needle technique and suction (Bergstrom 1975; Evans et al. 1982). Each 4-h biopsy was performed $2 \mathrm{~cm}$ proximal to the first location. Each trial utilized a different leg in randomized order. Before the biopsy, $1 \mathrm{~mL}$ of $1 \%$ lidocaine (without adrenaline) was injected beneath the skin as a local anesthetic. The initial lidocaine numbed a $2 \mathrm{~cm}^{2}$ area, wherein another $2-3 \mathrm{~mL}$ of lidocaine was injected near the fascia. Following the injection, an approximate $0.5 \mathrm{~cm}$ incision was made through the skin and muscle fascia. A Bergstrom biopsy needle was then inserted through the opening into the belly of the vastus lateralis muscle. This practice removed $30 \mathrm{mg}$ of tissue. Excess blood, fat, and connective tissue were subsequently separated from the muscle sample. Remaining tissue was immediately frozen in liquid nitrogen and stored at $-80{ }^{\circ} \mathrm{C}$ until muscle glycogen analysis.

\section{Blood sampling}

Venipuncture technique was used to collect blood samples from an antecubital vein at $0,30,120,150$, and $240 \mathrm{~min}$ of recovery. Samples were allowed to clot before being spun at $4000 \mathrm{rpm}$ for $15 \mathrm{~min}$ in a $4{ }^{\circ} \mathrm{C}$ refrigerated centrifuge (Jouan Inc., MR22i). Aliquots of serum were prepared and stored at $-30{ }^{\circ} \mathrm{C}$ until glucose and insulin analyses.

\section{Analysis}

An enzymatic spectrophotometric method was used to analyze duplicate muscle samples (10-12 mg) for muscle glycogen concentration (Ruby et al. 2005). Following weighing, samples were added to $0.5 \mathrm{~mL}$ of $2 \mathrm{~N} \mathrm{HCl}$ solution. This solution was weighed and incubated for $2 \mathrm{~h}$ in a $100^{\circ} \mathrm{C}$ oven. Following incubation, the samples were reweighed, reconstituted with distilled water to the original sample weight, and $\mathrm{pH}$ normalized using $1.5 \mathrm{~mL}$ of $0.67 \mathrm{M} \mathrm{NaOH}$, creating a muscle extract solution. $100 \mathrm{~mL}$ of muscle extract solution was added to $1 \mathrm{~mL}$ Infinity glucose (HK) liquid stable reagent (ThermoTrace Ltd.). Samples were read at $340 \mathrm{~nm}$ on a spectrophotometer, accommodating muscle glycogen concentration calculation using a standard curve. The concentration was expressed as $\mathrm{mM} \mathrm{kg}$ wet $\mathrm{wt}^{-1} \mathrm{~h}^{-1}$ of muscle.

Blood samples were similarly analyzed for glucose in triplicate with Infinity glucose (HK) liquid stable reagent (ThermoTrace Ltd.) and read at $340 \mathrm{~nm}$ on a spectrophotometer. A standard curve was used to calculate blood glucose 
concentration. An enzymatic spectrophotometric ELISA method was used to analyze insulin from blood samples in duplicate (EIA-2935, DRG International). Mean intra-assay coefficients of variation for muscle samples, glucose, and insulin using these techniques were less than $5 \%$.

\section{Statistical analysis}

Sex-specific demographics were analyzed via two-tailed independent $t$ tests (Microsoft Excel, Microsoft Corp., Redmond, WA, USA). Multiple two-way ANOVAs (sex $x$ trial order and sex $x$ trial) with repeated measures were used to analyze PTT and TT performance times (SPSS Inc., Chicago, IL, USA). Muscle glycogen recovery rates were compared using a two-way ANOVA (sex $\times$ trial) with repeated measures. A three-way ANOVA ( $\operatorname{sex} \times$ trial $\times$ time) with repeated measures was used to examine differences in muscle glycogen, blood glucose, and serum insulin levels between males and females (SPSS Inc., Chicago, IL, USA). Gastrointestinal discomfort and meal satisfaction were compared using a three-way ANOVA ( $\operatorname{sex} \times$ trial $\times$ time) with repeated measures. Statistical significance for all analyses was set at a probability of type I error less than $5 \%(p<0.05)$. Data in text and tables are expressed as mean \pm SD. Graphical data are expressed as mean \pm SEM.

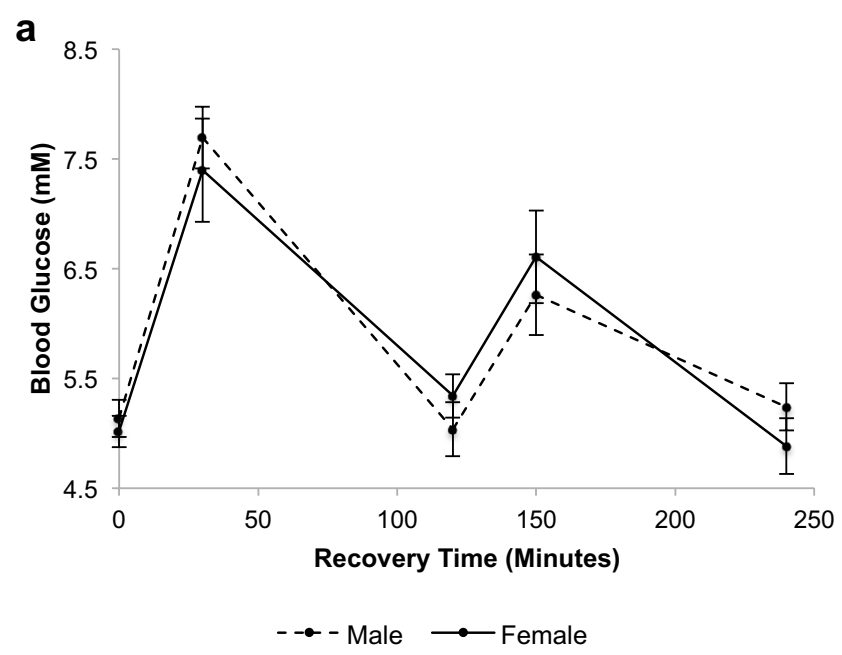

Fig. 2 Blood glucose concentration during recovery. a Between sexes ( $n=8$ males, $n=8$ females $)$. b Time $\times$ trial interaction $(p<0.05$, $n=16$ potato, $n=16$ supplement). a $p<0.01$ from 0 -min recovery

\section{Results}

\section{Subject descriptive data}

Sixteen subjects completed the study (eight males, eight females). Descriptive data are presented in Table 2. There was a significant difference between men and women for weight, fat-free mass (FFM), and $V \mathrm{O}_{2 \text { peak }}$ (absolute and relative). However, there was no difference between males and females for age, body fat percentage, or $\mathrm{VO}_{2 \text { peak }}$ when normalized for FFM.

\section{Blood glucose}

There was a time $\times$ trial interaction for blood glucose (Fig. 2, $p<0.05$ ). Blood glucose was elevated at 30 and $150 \mathrm{~min}$ (30 min post each feeding) for both PB and SS trials ( $p<0.0001$ and $p<0.01$ respectively). At $150 \mathrm{~min}$, blood glucose was significantly higher during the SS trial than the PB trial $(p<0.01)$. There was no sex difference in blood glucose at $0,30,120,150$, or 240 min post-exercise $(p>0.05)$ and no difference in blood glucose between the diets at 0 , 30,120 , or $240 \mathrm{~min}$ post-exercise $(p>0.05)$.

\section{Serum insulin}

There was a time $\times$ trial interaction for serum insulin (Fig. 3, $p<0.0001$ ). Insulin was elevated at 30 and 150 min post-meal consumption for both $\mathrm{PB}$ and SS trials $(p<0.05)$. The PB treatment demonstrated higher insulin at $120 \mathrm{~min}(p<0.05)$, while the SS treatment noted higher

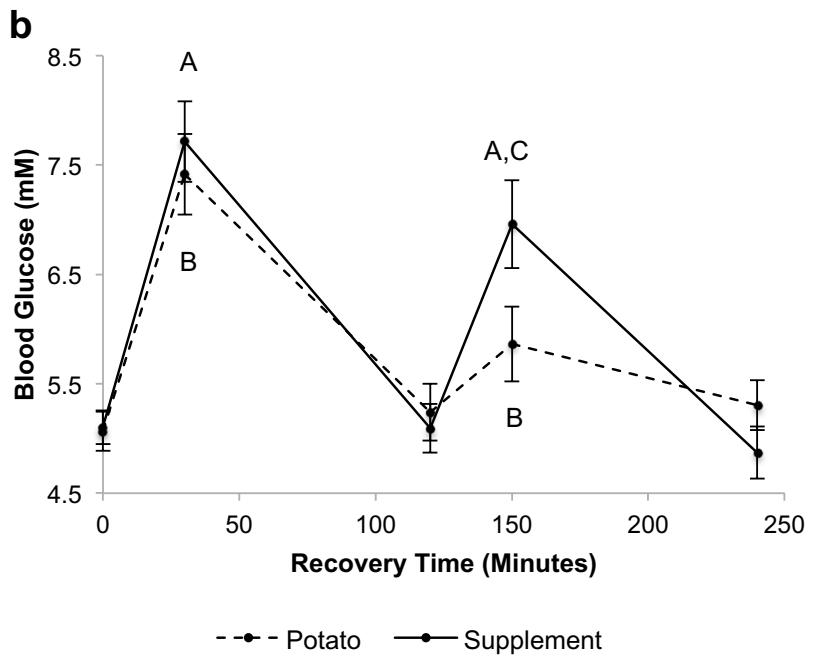

(supplement), b $p<0.0001$ from 0 -min recovery (potato), c $p<0.01$ supplement from potato. Values are mean \pm SEM 


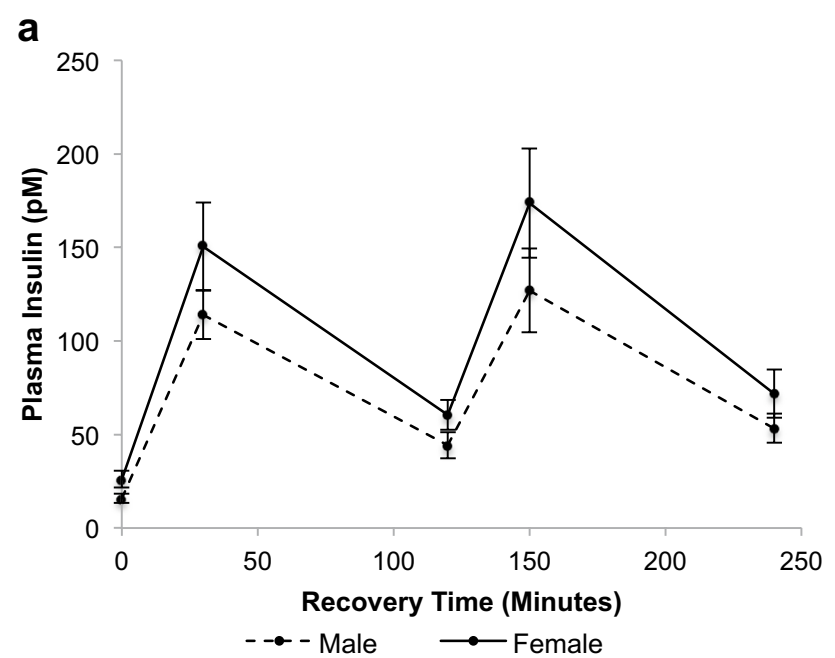

Fig. 3 Plasma insulin concentration during recovery. a Between sexes $(n=8$ males, $n=8$ females $)$. b Time $\times$ trial interaction $(p<0.0001$, $n=16$ potato, $n=16$ supplement). a $p<0.05$ from 0 -min recovery

insulin at $150 \min (p<0.05)$. There was no sexm difference in serum insulin at $0,30,120,150$, or 240 min postexercise $(p>0.05)$ and no difference in insulin between the diets at 0,30 , or $240 \mathrm{~min}$ post-exercise $(p>0.05)$.

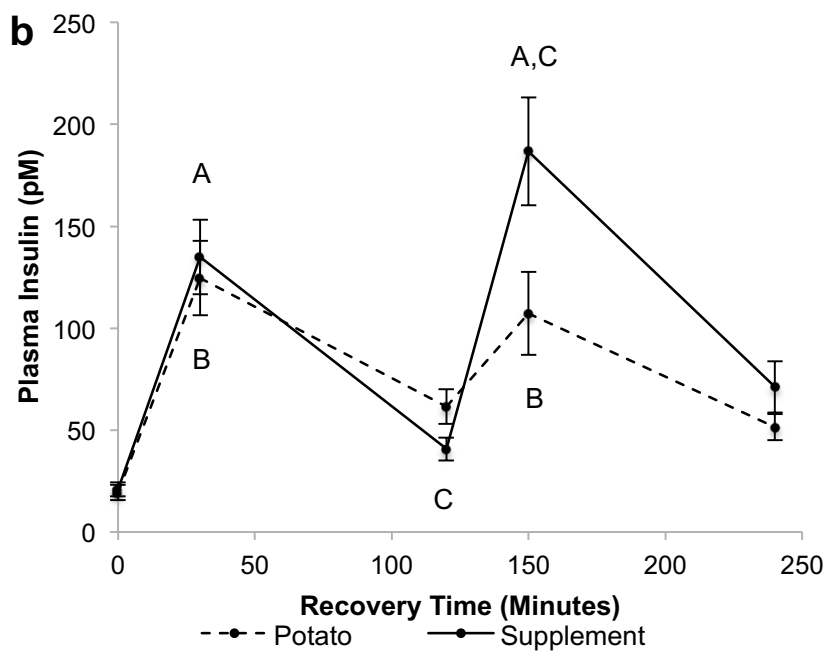

(supplement), b $p<0.05$ from 0 -min recovery (potato), c $p<0.05$ supplement from potato. Values are mean \pm SEM

\section{Muscle glycogen}

There was a main effect for time, where muscle glycogen content increased over the recovery period (Fig. 4, $p<0.0001)$. There was no difference in muscle glycogen content between males and females at $0 \mathrm{~h}$ or $4 \mathrm{~h}$ of recovery $(p>0.05)$. Correspondingly, there was no difference between males and females in the rate of glycogen re-synthesis (male:
Fig. 4 Muscle glycogen concentration during recovery. $* p<0.0001$ main effect for time from $0 \mathrm{~h}$ recovery. Values are mean \pm SEM

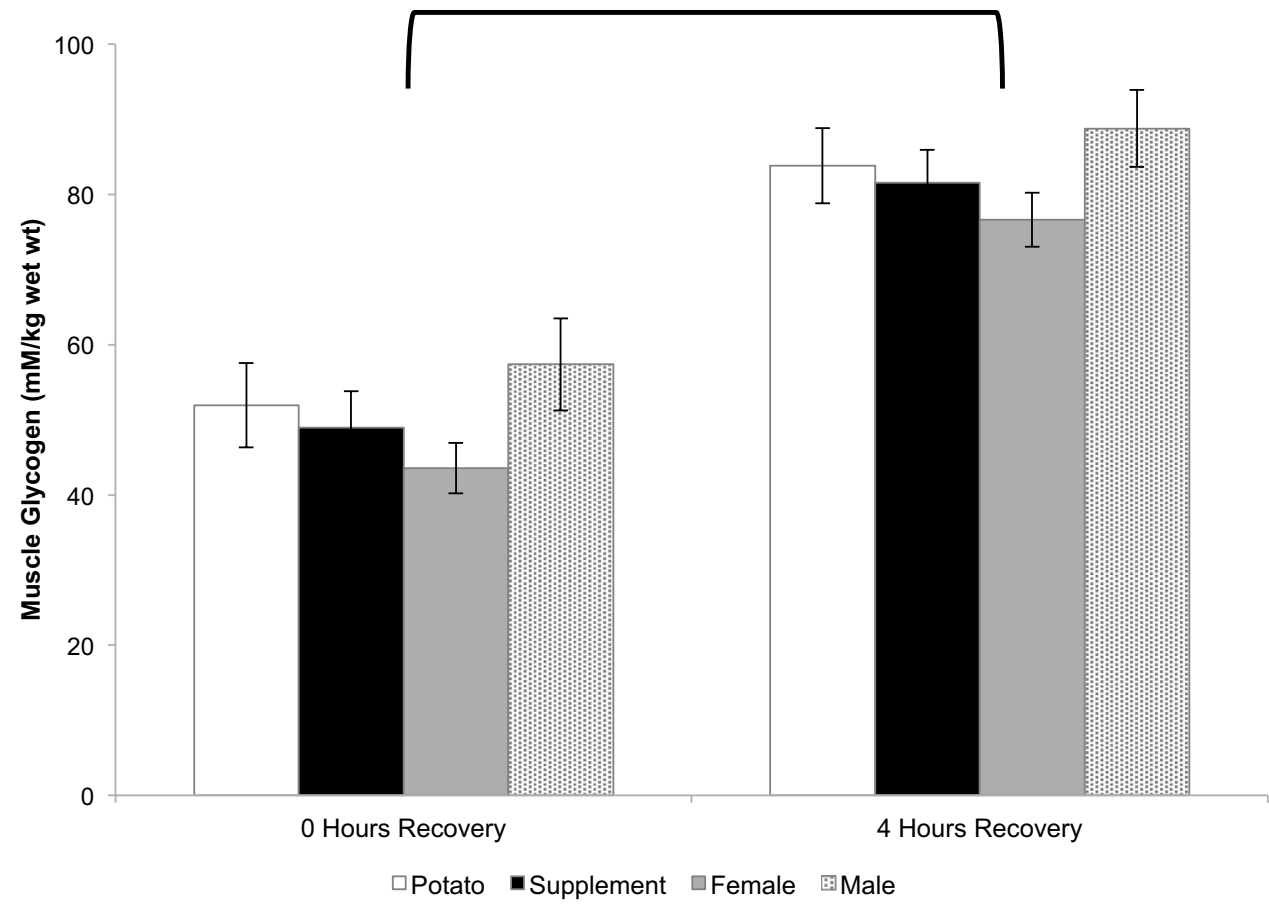


$7.9 \pm 2.7$, female: $8.2 \pm 2.7 \mathrm{mM} \mathrm{kg}$ wet $\mathrm{wt}^{-1} \mathrm{~h}^{-1}, p>0.05$ ). SS and PB displayed no differences in muscle glycogen content at $0 \mathrm{~h}$ or $4 \mathrm{~h}$ of recovery $(p>0.05)$ and no difference in the rate of muscle glycogen re-synthesis (PB: $8.0 \pm 2.5$, SS: $8.1 \pm 3.1 \mathrm{mM} \mathrm{kg}$ wet $\left.\mathrm{wt}^{-1} \mathrm{~h}^{-1}, p>0.05\right)$.

\section{Questionnaire}

For hunger, there was a main effect for time $(p<0.0001)$ and sex $(p<0.05)$. Participants rated hunger higher at $0 \mathrm{~h}$ and 2 $\mathrm{h}$ of recovery, which was before each meal $(0 \mathrm{~h}: 0.62 \pm 0.05$, $1 \mathrm{~h}: 0.45 \pm 0.04,2 \mathrm{~h}: 0.55 \pm 0.04,3 \mathrm{~h}: 0.32 \pm 0.04,4 \mathrm{~h}$ : $0.31 \pm 0.04$ VAS scores). Males rated hunger higher than females across trials (male: $0.53 \pm 0.05$, female: $0.36 \pm 0.05$ ). There was a trial $\times$ sex interaction for stomach discomfort $(p<0.05)$. Males had less stomach discomfort during the potato trial than the supplement trial (PB: $0.12 \pm 0.04$, SS: $0.20 \pm 0.06)$. In reference to meal satisfaction, there was a main effect for trial regarding how tasty $(p<0.0001)$, how satisfying $(p<0.01)$, and how acceptable $(p<0.05)$ the meals were. The PB were rated more tasty (PB: $0.65 \pm 0.04$, SS: $0.43 \pm 0.04$ ), satisfying (PB: $0.65 \pm 0.05$, SS: $0.45 \pm 0.05$ ), and more acceptable (PB: $0.59 \pm 0.04$, SS: $0.47 \pm 0.05)$ than the SS.

\section{$20 \mathrm{~km}$ time trial}

There was no interaction or main effect for trial when TT performance was analyzed for order (trial 1: $37.9 \pm 3.8$, trial 2: $37.6 \pm 4.1$, trial $3: 38.2 \pm 3.8$, trial $4: 37.9 \pm 4.4 \mathrm{~min}$, $p>0.05$ ) or practice and experimental trials (PTT1: $37.9 \pm 3.8$, РTT2: $37.6 \pm 4.1$, РBTT: $38.3 \pm 4.4$, SSTT: $37.8 \pm 3.9 \mathrm{~min}, p>0.05)$. This indicates there was no learning effect and no difference between SS and PB. However, there was a main effect for sex, with males completing the time trials significantly faster than females (male: $34.7 \pm 1.7$, female: $41.0 \pm 3.0 \mathrm{~min}, p<0.0001)$.

\section{Discussion}

Current recommendations for refueling after exercise can be misleading, in particular for recreational athletes who are targeted by commercial marketing (Heneghan et al. 2012; Zytnick et al. 2015). In the current study, males and females resynthesized muscle glycogen at similar rates following glycogen depletion and consumption of two different diets (potato-based food items and common sport supplement products), leading to minimal differences during subsequent exercise performance. When coupled with prior data using fast food items (Cramer et al. 2015), these recent data demonstrate that the exercise recovery carbohydrate oriented feeding recommendations given by health care providers, coaches and trainers can be simplified. Sport and tactical athletes of both sexes can choose a variety of desirable and/ or available carbohydrate sources as recovery foods/beverages. Moreover, the diversification of dietary strategies may enhance carbohydrate compliance and sustainability of energy intake.

Similarities between males and females corroborate the findings of Tarnopolsky et al. (1997) who observed comparable rates of post-exercise glycogen re-synthesis in similarly trained males and females $(25.5$ and $23.5 \mathrm{mM} \mathrm{kg}$ dry $\mathrm{wt}^{-1} \mathrm{~h}^{-1}$, respectively) when provided with a mixed macronutrient liquid feeding. Sex similarities in glycogen re-synthesis contradict suggestions that women require unique recovery feeding recommendations when compared to men (Black et al. 2019; Rehrer et al. 2017), indicating that consumers and athletes should be wary of sex-specific marketing related to carbohydrate-rich recovery products. Like Tarnopolsky et al. (1997), the current study found no significant difference between men and women in $\mathrm{VO}_{2 \text { peak }}$ when normalized for FFM. However, fitness in our study was lower for both sexes, underscoring the application of recovery recommendations across varied training statuses. A broadened application may be particularly important when considering recovery products that are often marketed to recreational athletes (Heneghan et al. 2012; Zytnick et al. 2015).

Eating before and/or during exercise would be typical of most extended training sessions and competitions for sports athletes and of most workplace scenarios for tactical athletes, while many laboratory investigations use a fasted state. Some research indicates that substrate use sex differences are eliminated when subjects exercise in a fed as opposed to fasted state (Harger-Domitrovich et al. 2007). The current study's sex similarity also aligns with findings that when men and women are matched for FFM and fitness, wholebody substrate use is similar during exercise (Roepstorff et al. 2002; Ruby et al. 2002a) and that females can supercompensate (or pre-load) their glycogen stores as effectively as males (James et al. 2001; Paul et al. 2001; Tarnopolsky and Ruby 2001; Walker et al. 2000). All of these results are logical when considering that GLUT-4, hexokinase, and glycogen synthase levels and activities are similar between men and women (Lundsgaard and Kiens 2014), which would contribute to limited differences in muscle glucose delivery and storage across sex. These established cellular level comparisons support the outward muscle recovery and subsequent exercise performance responses in the present group of males and females.

Since all of the females were using oral or IUD-derived exogenous hormones for birth control, it is difficult to consider a particular phase of the menstrual cycle. Indeed, past work has sought to control testing relative to the menstrual cycle for measures of glucose kinetics (Zderic et al. 2001; 
Ruby et al. 2002a, b) and glycogen use (Harger-Domitrovich et al. 2007). The effects of endogenous and/or exogenous estradiol has been demonstrated to reduce the rate of glucose appearance ( $\mathrm{Ra}$ ) and disappearance (Rd) during tightly controlled exercise trials under fasted conditions (Zderic et al. 2001; Ruby et al. 2002a, b; Ruby et al. 1997) but without altering total carbohydrate oxidation. Moreover, the data of Tarnopolsky et al. (2006) demonstrate minimal differences in post-exercise muscle glycogen values between the phases of the menstrual cycle. Despite the potential for hormone (specifically estradiol)-derived variations in substrate oxidation during exercise, it is unclear if the varied hormonal milieu may exert measurable effects on post-exercise carbohydrate delivery and deposition.

The lack of significant difference between PB and SS feedings for rates of glycogen re-synthesis or exercise performance demonstrates that diverse diets can similarly enhance glycogen recovery. The similarity in recovery despite varied carbohydrates extends upon a body of research supporting the use of common foods as an alternate or additional form of sport nutrition as compared to commercial products specifically marketed to improve recovery. Cramer et al. (2015) showed that fast food menu items stimulated glycogen recovery and contributed to subsequent exercise performance as effectively as commercial sports supplement products. Other research has demonstrated that golden raisins and chocolate milk are as effective as sports supplements for providing carbohydrate during (Rietschier et al. 2011) and after (Karp et al. 2006; Lunn et al. 2012; Pritchett et al. 2009; Thomas et al. 2009) exercise. While all of these investigations included a measure of performance, only Rietschier et al. (2011) measured blood glucose during exercise and Lunn et al. (2012) measured muscle glycogen during recovery. Importantly, during the current study, the PB diet was rated higher for taste and satisfaction than the SS and the PB led to lower feelings of sickness and stomach discomfort for males. The positive questionnaire ratings for PB as compared to SS indicate that it could be easier and more agreeable for athletes to consider commonplace foods rather than exclusively consume commercial products marketed as sport-specific recovery products. Evidence shows that many athletes, especially females, have a lower overall energy intake and consume less than the recommended amounts of carbohydrate (Baranauskas et al. 2015; Black et al. 2019; Burke et al. 2001; Masson and Lamarche 2016; Shriver et al. 2013). As a possible solution, dietary diversity tends to increase total caloric consumption (de Oliveira et al. 2018). If athletes are encouraged to consume a variety of foods they enjoy, the likelihood of carbohydrate compliance and sustainable dietary design may be enhanced. Simple recommendations may be particularly critical during situations where total daily energy expenditure meets or exceeds $3 \times$ BMR, such as for occupational athletes like wildland firefighters (Ruby et al. 2002b) or tactical athletes like Marines in combat scenarios (Hoyt et al. 1991).

The subtle differences in glucose and insulin in the current study did not impact the overall rate of glycogen resynthesis, showing that possible variances in carbohydrate digestion and absorption had limited effect on the delivery of carbohydrate to the muscle. Similar to other studies using a variety of feeding strategies (Ivy et al. 1988a, b, 2002), blood glucose and insulin rose quickly following the 0 and 2-h feedings before returning to baseline. While there was no difference in response between PB and SS at 30 min after the 0 -h feeding, there was a difference at $30 \mathrm{~min}$ after the 2-h feeding (150 min), with PB eliciting a significantly lower glucose and insulin response compared to SS. The different blood responses could result from differences in the factors impacting gastric emptying between the SS and PB for the 2-h feeding. Although gastric emptying was not measured in the current study, previous research shows that faster emptying can lead to quicker glucose absorption in the small intestine (Macdonald 1996). Other investigations indicate that gastric emptying is enhanced with decreased fat (Frost et al. 2003), fiber (Vincent et al. 1995), and increased liquids (Hellström et al. 2006). Although the SS and PB at both feedings were matched for fat and protein content, both PB had higher fiber content, while both SS had a higher portion of calories from liquid sources. The lack of difference in the glucose and insulin response following the 0 - $h$ feeding could indicate that gastric emptying has varying levels of influence based on timing. For example, directly following exercise, muscle glycogen is most depleted so gastric emptying may have less impact than after the 2-h feeding when glycogen re-synthesis has already commenced. Alternately, the different blood responses might be caused by differences in the content of simple sugars between the SS and PB for the 2-h feeding. While the 0 -h feedings had a similar proportion of carbohydrate calories from simple sugars, the SS meal at 2 $\mathrm{h}$ had a higher simple sugar content, potentially explaining our results. Regardless of the cause of subtle blood differences, the rates of overall muscle glycogen recovery were minimally affected.

The current study does not show evidence suggesting that females should be fed differently than males in regards to post-exercise carbohydrates outside of adjusting total carbohydrate content relative to total body mass ( $\mathrm{g}$ CHO per $\mathrm{kg}$ body mass). Nonetheless, there are some limitations. The investigation did not consider protein, fat, micronutrient, or specific amino acid needs that may differ between sexes. However, West et al. (2012) demonstrated minimal differences between males and females in myofibrillar protein synthesis (MPS) after resistance exercise when subjects were provided with $25 \mathrm{~g}$ of whey protein post-exercise. Moreover, the similarities in MPS between males and females occurred despite significantly higher testosterone in males. Although 
further research could consider whether recommendations for other nutrients should differ between males and females, it is important to link suggested recommendations to outward measures of exercise performance versus theoretical biomarkers of performance. It is also important to note that exogenous carbohydrate during exercise may alter endogenous depletion of glycogen (De Bock 2005) and rates of subsequent glycogen re-synthesis (Reinert et al. 2009). Our study utilized a fasted state, but athletes often work, train, and compete in a fed state, so additional research using alternate feeding strategies may be warranted. Finally, although we did not modify environmental conditions during the current study, consideration of other factors during recovery is critical. Recovering in room temperature ambient conditions (Naperalsky et al. 2010; Slivka et al. 2013) and with warmed muscles (Slivka et al. 2012; Tucker et al. 2012) will enhance glycogen re-synthesis as demonstrated by prior research on males. Environmental elements have not yet been investigated in women.

\section{Conclusion}

The findings of the current study regarding muscle glycogen re-synthesis and exercise performance can be applied to both male and female sport and tactical or occupational athletes of various fitness levels who require glycogen restoration following extended periods of work or between multiple bouts of work in a single day. As long as an adequate amount of carbohydrate $\left(1.6 \mathrm{~g} \mathrm{~kg}^{-1}\right)$ is provided at multiple intervals during recovery, the source of macronutrients for men and women may be diverse and need not be limited to exclusively commercial sport nutrition products. Variation in recovery food sources may enhance carbohydrate compliance, contributing to sustainable recovery dietary design. The uniformity and flexibility of these recommendations simplify and potentially decrease the cost of recovery feeding plans, a notion that may be particularly important for recreational athletes who may be susceptible to commercial marketing.

Acknowledgements The authors are grateful to the participants for their time and investment in the investigation. They also thank Tiffany Quindry for her assistance and the sharing of her lab and equipment.

Author contributions SKF participated in design, organization, data acquisition, and data interpretation. SKF also participated in muscle glycogen, blood, questionnaire, TT, and statistical analysis and wrote the manuscript. AMR participated in design, organization, data acquisition, and data interpretation. AMR also participated in muscle glycogen, blood, questionnaire, TT, and statistical analysis. WSH participated in conception, design, organization, data acquisition, and data interpretation. WSH also participated in muscle glycogen, blood, and statistical analysis. BCR participated in conception, design, data acquisition, data analysis, and data interpretation and aided in the drafting and revising of the manuscript. All authors have read and given final approval of this version of the manuscript for publication.

Funding This study was funded by the Alliance for Potato Research and Education.

\section{Compliance with ethical standards}

Conflict of interest The authors declare no competing interests in access to these data. They also declare no associations with companies involved with the products used in the investigation.

Open Access This article is licensed under a Creative Commons Attribution 4.0 International License, which permits use, sharing, adaptation, distribution and reproduction in any medium or format, as long as you give appropriate credit to the original author(s) and the source, provide a link to the Creative Commons licence, and indicate if changes were made. The images or other third party material in this article are included in the article's Creative Commons licence, unless indicated otherwise in a credit line to the material. If material is not included in the article's Creative Commons licence and your intended use is not permitted by statutory regulation or exceeds the permitted use, you will need to obtain permission directly from the copyright holder. To view a copy of this licence, visit http://creativecommons.org/licenses/by/4.0/.

\section{References}

Ahlborg B, Bergstrom J, Edelund L, Hultman E (1967) Muscle glycogen and muscle electrolytes during prolonged physical exercise. Acta Physiol 70:129-142

American College of Sports Medicine (2013) ACSM's guidelines for exercise testing and prescription. Lippincott Williams \& Wilkins, Philadelphia

Baranauskas M, Stukas R, Tubelis L et al (2015) Nutritional habits among high-performance endurance athletes. Medicina $51: 351-362$

Bergstrom J (1975) Percutaneous needle biopsy in physiological and clinical research. Scand J Clin Lab Investig 35:609-616

Bergstrom J, Hermansen L, Hultman E, Saltin B (1967) Diet, muscle glycogen, and physical performance. Acta Physiol 71:140-150

Black KE, Baker DF, Sims ST (2019) Nutritional needs of the female athlete: risk and prevention of low energy availability. Strength Cond J. https://doi.org/10.1519/ssc.0000000000000464

Blom P, Hostmark AT, Vaage O, Kardel KR, Maehlum S (1987) Effect of different post-exercise sugar diets on the rate of muscle glycogen synthesis. Med Sci Sports Exerc 19:491-496

Burke LM, Collier GR, Hargreaves M (1993) Muscle glycogen storage after prolonged exercise: effect of the glycemic index of carbohydrate feedings. J Appl Physiol 75:1019-1023

Burke LM, Cox GR, Cummings NK, Desbrow B (2001) Guidelines for daily carbohydrate intake: do athletes achieve them? Sports Med 31:267-299

Cramer MJ, Dumke CL, Hailes WS, Cuddy JS, Ruby BC (2015) Postexercise glycogen recovery and exercise performance is not significantly different between fast food and sport supplements. Int $\mathbf{J}$ Sport Nutr Exerc Metab 25:448-455

De Bock K (2005) Exercise in the fasted state facilitates fibre typespecific intramyocellular lipid breakdown and stimulates glycogen resynthesis in humans. J Physiol 564:649-660

de Oliveira OM, Anderson C, Dearborn J et al (2018) Dietary diversity: implications for obesity prevention in adult populations: a 
science advisory from the American Heart Association. Circulation 138:e160-e168

Devries MC (2016) Sex-based differences in endurance exercise muscle metabolism: impact on exercise and nutritional strategies to optimize health and performance in women. Exp Physiol 101:243-249

Devries MC, Hamedeh MJ, Phillips SA, Tarnopolsky MA (2006) Am J Physiol Regul Integr Comp Physiol 291:R1120-R1128

Evans WJ, Phinney SD, Young VR (1982) Suction applied to a muscle biopsy maximizes sample size. Med Sci Sports Exerc 14:101-102

Frost GS, Brynes AE, Dhillo WS, Bloom SR, McBurney MI (2003) The effects of fiber enrichment of pasta and fat content on gastric emptying, GLP-1, glucose, and insulin responses to a meal. Eur J Clin Nutr 57:293-298

Goldman HI, Becklake MR (1959) Respiratory function tests; normal values at median altitudes and the prediction of normal results. Am J Tuberc 79:457-467

Harger-Domitrovich SG, McClaughry AE, Gaskill SE, Ruby BC (2007) Exogenous carbohydrate spares muscle glycogen in men and women during $10 \mathrm{~h}$ of exercise. Med Sci Sports Exerc 39:2171-2179

Hellström PM, Grybäck P, Jacobsson H (2006) The physiology of gastric emptying. Best Pract Res Clin Anaesthesiol 20:397-407

Heneghan C, Howick J, O'Neill B et al (2012) The evidence underpinning sports performance products: a systematic assessment. BMJ Open 2:e001702

Hoyt RW, Jones TE, Stein TP et al (1991) Doubly labeled water measurement of human energy expenditure during strenuous exercise. J Appl Physiol 71:16-22

Ivy JL, Goforth HJ, Damon BM, McCauley TR, Parson EC, Price TB (2002) Early postexercise muscle glycogen recovery is enhanced with a carbohydrate-protein supplement. J Appl Physiol 93:1337-1344

Ivy JL, Katz AL, Cutler CL, Sherman WM, Coyle EF (1988a) Muscle glycogen synthesis after exercise: effect of time of carbohydrate ingestion. J Appl Physiol 64:1480-1485

Ivy JL, Lee MC, Brozinick JJ, Reed MJ (1988b) Muscle glycogen storage after different amounts of carbohydrate ingestion. J Appl Physiol 65:2018-2023

James AP, Lorraine M, Cullen D et al (2001) Muscle glycogen supercompensation: absence of a gender-related difference. Eur J Appl Physiol 86:533-538

Jentjens RLPJ, van Loon LJC, Mann CH, Wagenmakers AJM, Jeukendrup AE (2001) Addition of protein and amino acids to carbohydrates does not enhance postexercise muscle glycogen synthesis. J Appl Physiol 91:839-846

Karp JR, Johnston JD, Tecklenburg S, Mickleborough TD, Fly AD, Stager JM (2006) Chocolate milk as a post-exercise recovery aid. Int J Sport Nutr Exerc Metab 16:78-91

Kions B, Raben AB, Valeur AK (1990) Benefit of dietary simple carbohydrates on the early post-exercise muscle glycogen repletion in male athletes. Med Sci Sports Exerc 22:S88

Kissileff HR, Carretta JC, Geliebter A, Pi-Sunyer FX (2003) Cholecystokinin and stomach distension combine to reduce food intake in humans. Am J Physiol Regul Integr Comp Physiol 285:R99-R998

Lundsgaard A, Kiens B (2014) Gender differences in skeletal muscle substrate metabolism: molecular mechanisms and insulin sensitivity. Front Endocrinol 5:195

Lunn WR, Pasiakos SM, Colletto MR et al (2012) Chocolate milk and endurance exercise recovery: protein balance, glycogen, and performance. Med Sci Sports Exerc 44:682-691

Macdonald IA (1996) Physiological regulation of gastric emptying and glucose absorption. Diabet Med 13:S11-S15

Masson G, Lamarche B (2016) Many non-elite multisport endurance athletes do not meet sports nutrition recommendations for carbohydrates. Appl Physiol Nutr Metab 41:728-734
Naperalsky M, Ruby B, Slivka D (2010) Environmental temperature and glycogen resynthesis. Int J Sports Med 31:561-566

Paul DR, Mulroy SM, Horner JA, Jacobs KA, Lamb DR (2001) Carbohydrate-loading during the follicular phase of the menstrual cycle: effects on muscle glycogen and exercise performance. Int J Sports Nutr Exerc Metab 22:430-441

Price TB, Rothman DL, Taylor R, Avison MJ, Shulman GI, Shulman RG (1994) Human muscle glycogen resynthesis after exercise: insulin-dependent and -independent phases. J Appl Physiol 76:104-111

Pritchett K, Bishop P, Pritchett R, Green M, Katica C (2009) Acute effects of chocolate milk and a commercial recovery beverage on postexercise recovery indices and endurance cycling performance. Appl Physiol Nutr Metab 34:1017-1022

Reed MJ, Brozinick JJ, Lee MC, Ivy JL (1989) Muscle glycogen storage postexercise: effect of mode of carbohydrate administration. J Appl Physiol 66:720-726

Rehrer NJ, McLay-Cooke RT, Sims ST (2017) Nutritional strategies and sex hormone interactions in women. In: Hackney AC (ed) Sex hormones, exercise and women. Springer, Cham, pp 87-112

Reinert A, Slivka D, Cuddy J, Ruby B (2009) Glycogen synthesis after road cycling in the fed state. Int J Sports Med 30:545-549

Riddell MC, Partington SL, Stupka N, Armstrong D, Rennie C, Tarnopolsky MA (2003) Substrate utilization during exercise performed with and without glucose ingestion in female and male endurancetrained athletes. Int J Sports Nutr Exerc Metab 13:407-421

Rietschier H, Henagan T, Earnest C, Baker B, Cortez C, Stewart L (2011) Sun-dried raisins are a cost-effective alternative to sports jelly beans in prolonged cycling. J Strength Cond Res 25:3150-3156

Roepstorff C, Steffensen CH, Stallknecht B, Kanstrup I, Richter EA, Kiens B (2002) Gender differences in substrate utilization during submaximal exercise in endurance-trained subjects. Am J Physiol 282:E435

Ruby BC, Robergs RA, Waters DL, Burge M, Mermier CM (1997) Effects of acute estrogen replacement on substrate utilization in amenorrheic females. Med Sci Sports Exerc 29:1160-1169

Ruby BC, Gaskill SE, Slivka D, Harger SG (2005) Addition of a fenugreek extract to glucose feedings increases muscle glycogen resynthesis after exercise. Amino Acids 28:71-76

Ruby BC, Coggan AR, Zderic TW (2002a) Gender differences in glucose kinetics and substrate oxidation during exercise near the lactate threshold. J Appl Physiol 92:1125-1132

Ruby BC, Shriver TC, Zderic TW, Sharkey BJ, Burks C, Tysk S (2002b) Total energy expenditure during arduous wildfire suppression. Med Sci Sports Exerc 34:1048-1054

Shriver LH, Betts NM, Wollenberg G (2013) Dietary intakes and eating habits of college athletes: are female college athletes following the current sports nutrition standards? J Am Coll Health 61:10-16

Slivka D, Tucker T, Cuddy J, Hailes W, Ruby B (2012) Local heat application enhances glycogenesis. Appl Physiol Nutr Metab 37:247-251

Slivka D, Heesch M, Dumke C, Cuddy J, Hailes W, Ruby B (2013) Effects of post-exercise recovery in a cold environment on muscle glycogen, PGC- $1 \alpha$, and downstream transcription factors. Cryobiology 66:250-255

Tarnopolsky M, Ruby B (2001) Sex differences in carbohydrate metabolism. Curr Opin Clin Nutr Metab Care 4:521-526

Tarnopolsky MA, Bosman M, Macdonald JR, Vandeputte D, Martin J, Roy BD (1997) Postexercise protein-carbohydrate and carbohydrate supplements increase muscle glycogen in men and women. J Appl Physiol 83:1877-1883

Tarnopolsky MA, Zawada C, Richmond LB et al (2001) Gender differences in carbohydrate loading are related to energy intake. J Appl Physiol 91:225-230 
Tarnopolsky MA (2008) Sex differences in exercise metabolism and the role of 17-beta estradiol. Med Sci Sports Exerc 40:648-654

Thomas K, Morris P, Stevenson E (2009) Improved endurance capacity following chocolate milk consumption compared with 2 commercially available sport drinks. Appl Physiol Nutr Metab 34:78-82

Tucker TJ, Slivka DR, Cuddy JS, Hailes WS, Ruby BC (2012) Effect of local cold application on glycogen recovery. J Sport Med Phys Fit 52:158-164

van Loon LJC, Saris WHM, Kruijshoop M, Wagenmakers AJM (2000) Maximizing postexercise muscle glycogen synthesis: carbohydrate supplementation and the application of amino acid or protein hydrolysate mixtures. Am J Clin Nutr 72:106-111

Vincent R, Roberts A, Frier M, Perkins AC, MacDonald IA, Spiller RC (1995) Effect of bran particle size on gastric emptying and small bowel transit in humans: a scintigraphic study. Gut 37:216-219

Walker JL, Heigenhauser JF, Hultman E, Spriet LL (2000) Dietary carbohydrate, muscle glycogen content, and endurance performance in well-trained women. J Appl Physiol 88:2151-2158

West DW, Burd NA, Churchward-Venne TA, Camera DM, Mitchell CJ, Baker SK, Hawley JA, Coffey VG, Phillips SM (2012) Sex-based comparisons of myofibrillar protein synthesis after resistance exercise in the fed state. J Appl Physiol 112:1805-1813

Zachwieja JJ, Costill DL, Pascoe DD, Robergs RA, Fink WJ (1991) Influence of muscle glycogen depletion on the rate of resynthesis. Med Sci Sports Exerc 23:44-48

Zawadski KM, Yaspelkis BB, Ivy JL (1992) Carbohydrate-protein complex increases the rate of muscle glycogen storage after exercise. J Appl Physiol 72:1854-1859

Zytnick D, Park S, Onufrak SJ, Kingsley BS, Sherry B (2015) Knowledge of sugar content of sports drinks is not associated with sports drink consumption. Am J Health Promot 30:101-108

Publisher's Note Springer Nature remains neutral with regard to jurisdictional claims in published maps and institutional affiliations. 